\title{
ANTROPÔNIMOS E MEMÓRIA: O LÉXICO ENQUANTO POSSIBILIDADE DE RESGATE DA HISTÓRIA SOCIAL POR MEIO DA ANÁLISE DO NOME PRÓPRIO
}

\author{
ANTHROPONYMS AND MEMORY: THE LEXICON AS A \\ POSSIBILITY OF REDEMPTION OF SOCIAL HISTORY \\ THROUGH ANALYSIS OF THE PROPER NAME
}

\author{
Carla BASTIANI*
}

Resumo: Este estudo propõe realizar uma reflexão acerca da possibilidade de se resgatar a história social de um determinado grupo por meio da análise dos antropônimos (nomes próprios) que nomeiam os estabelecimentos em geral que fazem parte do contexto de tal grupo, já que por meio dessa análise é possível resgatar informações sobre o caráter sociocultural e geográfico de uma região, bem como resgatar episódios históricos que foram importantes para a comunidade. O resgate da memória local visando ao conhecimento da comunidade de sua identidade sociocultural só se torna possível com a utilização da memória oral como fonte primeira de dados, uma vez que é no conhecimento dos moradores antigos que se encontra um meio de resgatar e conhecer a memória local de uma região. O objetivo central é evidenciar a importância de conhecer a motivação dos antropônimos que designam locais em uma comunidade como forma de preservar a memória do grupo.

Palavras-chave: Onomástica. Antropônimos. Memória Oral.

Abstract: This study proposes to conduct a reflection on the possibility of rescuing the social history of a particular group by analyzing the anthroponyms (proper names) which appointing the establishments which are part of the overall context of this group, since by through this analysis it is possible to retrieve information about the socio-cultural and geographical character of a region, as well as rescuing historical episodes that were important to the community. The recovery of local memory aiming at knowledge of their socio-cultural identity community is only possible with the use of oral history as the first data source, since it is the knowledge of the ancient inhabitants who finds a way to rescue and meet the memory location of a region. The main objective is to highlight the importance of knowing the motivation of local anthroponyms designating a community as a way to preserve the memory of the group.

Keywords: Onomastics. Anthroponyms. Oral memory.

\section{Introdução}

Refletir a respeito dos nomes em geral não é algo que usualmente faça parte de nossas inquietações primeiras. Pelo fato de os nomes estarem vinculados de modo indissolúvel às nossas vidas, permearem todas as relações que estabelecemos com o meio como um todo, o ato de pensar sobre eles de forma gratuita não é uma preocupação central.

\footnotetext{
* Mestranda em Ensino de Língua e Literatura pelo Programa de Pós-Graduação em Letras da Universidade Federal do Tocantins (UFT). E-mail: carlabastiani@gmail.com.
} 
Se restringirmos nossas atenções ao nome, mais especificamente ao nome próprio de pessoas, na qualidade de designativo geográfico ou de locais, veremos que essa situação pouco ou nada se altera. A indagação sobre o porquê da escolha desses nomes quase nunca faz parte das interrogações dos sujeitos.

É de conhecimento geral que é prática comum denominar cidades, ruas, espaços e estabelecimento com nomes próprios de pessoas, todavia a razão que impeliu o denominador a escolher um determinado nome ao invés de outro é algo que nem sempre fica transparente. A motivação do denominador nem sempre é conhecida pelos membros de uma comunidade. Em se tratando de nomes próprios de pessoas enquanto designativos geográficos, percebe-se que a escolha do nome nunca é feita de modo aleatório, pois o que move o denominador a eleger um determinado nome é a importância que escolhido representa para a história nacional ou local.

Quando esses nomes referenciam consagradas personalidades históricas, a sua escolha é mais facilmente compreendida. Já quando os nomes são concernentes a pessoas que um dia integraram a própria comunidade, geralmente, a importância daquela pessoa (cujo nome se tornou um designativo) é desconhecida por grande parte da população, de modo que desvelar a memória intrínseca a esses nomes constitui uma fonte de conhecimento da história da própria comunidade. Assim sendo, o que se pretende neste estudo é procurar pensar o nome próprio enquanto possibilidade de resgate e preservação da história social da comunidade.

Não é possível explicar a linguagem desvinculada de sua vertente social. É por meio da linguagem que o homem se comunica, organiza e estrutura seu pensamento, expressa e defende seus pontos de vista, produz conhecimento. Considerando essa dimensão social da língua, é possível ver no léxico o repertório cultural de uma comunidade.

Uma das preocupações da Lexicologia, ciência que tem como objeto de investigação científica o léxico de uma determinada língua natural, é analisar as relações do léxico com o contexto ambiental, histórico-político e cultural da comunidade, buscando examinar a palavra como testemunho de uma época. Biderman (2001) observa que o léxico "constitui uma forma de registrar o conhecimento do universo", ressaltando que:

Ao dar nomes aos seres e objetos, o homem os classifica simultaneamente. Assim, a nomeação da realidade pode ser considerada como etapa primeira no percurso científico humano de conhecimento do universo. Ao reunir os objetos em entidades diferentes, o homem foi estruturando o mundo que o 
cerca, rotulando essas entidades discriminadas. Foi esse processo de nomeação que gerou o léxico das línguas naturais (BIDERMAN, 2001, p. $13)$.

Levando em consideração a afirmação acima, cumpre mencionar que, por meio do estudo do patrimônio lexical de uma língua, é possível apreender as manifestações culturais e a cosmovisão do grupo que o utiliza, uma vez que os signos linguísticos são permeados por traços da cultura, história, valores e crenças desse grupo. Seguindo essa mesma linha de pensamento, Oliveira e Isquerdo (2001) reforçam que:

O léxico, saber partilhado que existe na consciência dos falantes de uma língua, constitui-se no acervo do saber vocabular de um grupo sóciolinguístico-cultural. Na medida em que o léxico configura-se como a primeira via de acesso a um texto, representa a janela através da qual uma comunidade pode ver o mundo, uma vez que esse nível da língua é o que mais deixa transparecer os valores, as crenças, os hábitos e costumes de uma comunidade, como também, as inovações tecnológicas, transformações socioeconômicas e políticas ocorridas numa sociedade (OLIVEIRA; ISQUERDO, 2001, p. 09).

Cabe à lexicologia, enquanto ciência da linguagem, o estudo do patrimônio lexical de uma determinada língua sob diversos aspectos. A Onomástica, integrando-se à lexicologia, possui como objeto de estudo o processo denominativo, ou seja, o estudo dos nomes próprios. Ela possui duas áreas de estudo: toponímia e antroponímia. A primeira estuda os nomes próprios de lugares e designativos geográficos; a segunda se ocupa dos nomes próprios de pessoa, possuindo grande relevância para a história política e cultural da sociedade.

Dick (1990) definiu os topônimos como sendo:

Verdadeiros 'testemunhos históricos' de fatos e ocorrências registrados nos mais diversos momentos da vida de uma população, encerram, em si, um valor que transcende ao próprio ato de nomeação: se a Toponímia situa-se como a crônica de um povo, gravando o presente para o conhecimento das gerações futuras, o topônimo é o instrumento dessa projeção temporal. Chega, muitas vezes, a se espalhar além de seu foco originário, dilatando, consequentemente, as fronteiras políticas, e criando raízes em sítios distantes. Torna-se, pois, a reminiscência de um passado talvez esquecido, não fora a sua presença dinâmica (DICK, 1990, p. 22).

Nesse sentido, cumpre assinalar que o topônimo não é algo estranho a conjuntura sociopolítica e cultural da comunidade. Ao contrario, pode ser considerado um registro temporal da cosmovisão de um determinado grupo social, uma vez que ao nome se incorporam vestígios da identidade e da história desse grupo.

Carvalhinhos (2003), ao discorrer sobre o resgate da história social possibilitado pelos estudos onomásticos, esclarece que:

Os atuais estudos onomásticos no Brasil vêm justamente resgatando a história social contida nos nomes de uma determinada região, partindo da etimologia 
para reconstruir os significados e, posteriormente, traçar um panorama motivacional da região em questão, como um resgate ideológico do denominador e preservação do fundo de memória. Nesse sentido, uma área toponímica pode ser comparada a um sítio arqueológico: podemos reconstruir, através do estudo de significados cristalizados de nomes de lugar, fatos sociais desaparecidos, contribuindo com material valioso para outras disciplinas, como a história, a geografia humana e a antropologia (CARVALHINHOS, 2003, p. 172).

Tendo como referência a fala da autora acima, cabe ressaltar que, por meio do estudo toponímico e antroponímico, é possível resgatar informações sobre o caráter sociocultural e geográfico de uma região, bem como resgatar episódios históricos que foram importantes para a comunidade, haja vista que estas ciências "são corresponsáveis pela preservação dos fatos culturais em determinado espaço-temporal, funcionando como detentoras da memória de um grupo". (ANDRADE, 2010, p. 101). Essas duas ciências podem exercer o papel de ferramentas para o conhecimento da história social de um determinado grupo, bem como da maneira pela qual esse grupo representa seus valores.

\section{Antroponímia e memória: um enlace para o resgate da história social da comunidade}

A antroponímia, do mesmo modo que a toponímia, apresenta-se como um caminho para o conhecimento da história da comunidade, uma vez que os nomes próprios, antropônimos, atribuídos a cidades, ruas, espaços ou estabelecimentos são imbuídos de motivações antropoculturais que se mostraram, em um determinado momento, importantes para o denominador.

Os topônimos, na qualidade de designações dos espaços por meio de nomes próprios, fazem parte da onomástica, subcomponente da figurativização. Juntamente com os antropônimos e os cronônimos, permite uma ancoragem histórica que visa a constituir o simulacro de um referente externo e a produzir o efeito de sentido 'realidade' (GREIMAS, 1989, p. 464).

Percebe-se, assim, que o léxico toponímico, enquanto expressão linguísticosocial, encontra-se enraizado à história, à tradição e aos costumes de um povo, de modo que o topônimo se apresenta como um meio que auxilia na compreensão da própria ideologia do denominador, da sua cosmovisão perante ao meio. Carvalhinhos (2007) endossa a citação acima ao afirmar que [...] "o nome é muito mais que um mero identificador ou uma etiqueta, é antes um vasto campo de estudo e um convite a entender as sociedades que o geraram, numa perspectiva diacrônica, e as que o utilizam, em perspectiva sincrônica". 
É prática comum em qualquer cidade brasileira nomear instituições e espaço públicos com antropôtonimos, isto é, com nomes próprios de pessoas. Os antropôtonimos escolhidos podem fazer alusão a personalidades históricas ou a pessoas da própria comunidade, sujeitos que politicamente ou religiosamente exerceram influência na região. No último caso, é uma prova de reconhecimento aos serviços prestados à comunidade por esses indivíduos.

Algumas vezes, porém, o que impeliu o denominador a designar um determinado local com um antropotopônimo é desconhecido por grande parte da comunidade, ou seja, a memória subjacente ao nome próprio não fica clara. Se esses nomes não fazem referência a personalidades históricas consagradas, geralmente a importância daquela pessoa (cujo nome se tornou um designativo) mergulha no abismo do esquecimento da população, ou seja, ignora-se o fato de que os homenageados um dia integraram a comunidade e a ela prestaram serviços de grande valia e que, por essa razão, tiveram seus nomes indelevelmente gravados nesses espaços.

Cumpre mencionar que antropotopônimos que designam espaços não são escolhidos ao acaso, ou seja, de modo aleatório em um eixo paradigmático de possibilidades, de forma contrária, há várias questões sociopolíticas e culturais que permeiam essas escolhas. Há sempre um motivo maior que leva o denominador a selecionar um determinado nome entre tantos outros existentes. Uma complexa rede de influências incide sobre essa escolha, de modo que a opção que melhor se adequar as necessidades presentes do denominador será a selecionada.

Ao refletir sobre isso, merece ênfase o fato que o reconhecimento da importância exercida por determinado sujeito pela escolha de seu nome para batizar um local não resiste à inexorável ação do tempo. Quando se trata do legado deixado por um nome próprio, a homenagem se torna deveras mais fácil de ser apagada, já que o nome está sujeito às ações do tempo, influências, alteração e, até mesmo, o esquecimento do significado original. Se não for empreendido um trabalho que vise ao resgate da memória evocada pelo antropotopônimo, corre-se o risco de perder uma parcela significativa da história social da comunidade.

Assim, indivíduos que em um determinado período histórico foram importantes para o grupo social, seja pelo trabalho que desenvolveram, seja pelo exemplo de conduta moral, seja por qualquer outra razão, têm sua história ignorada pela posteridade. Sobre a relação do indivíduo com o passado e com a história social, os Parâmetros Curriculares Nacionais para o ensino médio (2006) explicam que: 
A nossa relação com o instituído não deve ser, portanto, de querer destruí-lo ou cristalizá-lo. Sem um olhar sobre o instituído, criamos lacunas, desfiguramos memórias e identidades, perdemos vínculo com a nossa história, quebramos os espelhos que desenham nossas formas. A modernidade, por mais crítica que tenha sido da tradição, arquitetou-se a partir de referências e paradigmas seculares. A relação com o passado deve ser cultivada, desde que se exerça uma compreensão do tempo como algo dinâmico, mas não simplesmente linear e sequencial (BRASIL, 2006, p. 90).

Nesse sentido, buscar conhecer a motivação dos antropônimos que designam espaços em uma comunidade, em alguns casos, permite reconstruir um pouco da identidade cultural da região, como, por exemplo, em cidades que possuem grande parte de seus estabelecimentos e espaços públicos: instituições escolares, bibliotecas, hospitais, postos de saúde, praças, entre outros, batizados com nomes de pessoas ilustres para a sociedade local.

Cumpre mencionar que desvelar a memória intrínseca a um nome próprio não é uma tarefa fácil. A metodologia toponímica, pautada nas propostas de Dick (1990), se desenvolve mediante um plano onomasiológico de investigação, de modo que, por meio de um conceito genérico, se identificam as variáveis possíveis das fontes consultadas. Além disso, a recuperação dos nomes de lugares dá-se por meio da conjugação de dois tipos de fontes: os documentos oficiais e as declarações de moradores antigos, complementares e necessárias à reconstrução do patrimônio cultural de uma região e viabilizadoras do estreitamento da relação de sentido existente entre os indivíduos e os nomes próprios dos locais que os circundam.

Em se tratando do resgate da memória dos antropônimos, muitas vezes, os documentos históricos oficiais não são suficientes, pela escassez de informações que possuem, de modo que a memória oral desempenha papel crucial nesse trabalho. Assim sendo, a realização de entrevistas com os moradores mais antigos de uma região possibilita trazer à tona fatos até então desconhecidos pela comunidade e que podem ser de suma importância para a compreensão da escolha de um determinado nome.

Levando em consideração o já mencionado fato de que ao ato de nomear impregnam-se marcas sociais, históricas e culturais de uma dada comunidade e, ao se estudar essa nomeação, essas marcas e todo o contexto desse grupo social à época da denominação emergem, cumpre ressaltar que a memória oral cumpre o papel crucial de subsidiar o trabalho de resgate da identidade sociocultural a partir da análise dos antropônimos atribuídos aos estabelecimentos de uma dada cidade; memória oral essa que, nas palavras de Benjamin (1994), “é a mais épica de todas as faculdades”, uma vez 
que "o narrador retira da experiência o que ele conta: sua própria experiência ou a relatada pelos outros".

Em nossos dias, o pretenso conhecimento sobre a realidade tem se desenvolvido em meios restritos e impregnado por ideologias que orientam sua veiculação aos meios considerados não cultivados. A memória oral resiste a esse saber que mais se aproxima da verdade por necessidade. $\mathrm{O}$ direito à narração alarga o debate sobre o vivido e conserva um mundo acolhedor de olhares geralmente impedidos de ascender à condição política. Assim considerando, transforma- se o caráter do que podemos tomar por conhecimento sobre o passado. $\mathrm{O}$ que supomos como verdade não mais abrange uma conclusão definitiva e universal como requisito de sua validade. Antes, o pregresso permanece aberto e provisório, sujeito à experiência de morada na perspectiva de outro amigo (FROCHTENGARTEN, 2005, p. $373)$.

A memória é a principal fonte de conhecimento dessa realidade, sendo a oralidade o instrumento utilizado na transmissão de conhecimentos e na manutenção dos saberes adquiridos ao longo do tempo, e que são transmitidos aos demais por meio da memória, uma vez que todo grupo tem um saber cumulativo de si oriundo da memória, que é empregado na linguagem, já que o tipo de cultura é determinado pelo uso que uma sociedade faz da memória. Afirmação confirmada por Halbwachs (2006) ao salientar que "a memória individual existe sempre a partir de uma memória coletiva". Segundo esse autor, há um caráter social na memória, de modo que as memórias de um indivíduo nunca existem de forma autônoma em relação à sociedade.

A memória individual está relacionada à lembrança de um acontecimento por um ator que dela participou ou foi ouvinte e que é capaz de relatar o ocorrido ou mesmo reter essa informação. Trata-se da noção de memória enquanto armazenamento de informações. Dessa noção, surge a ideia de que para um fato se eternizar e se transformar em memória para um grupo é necessário que haja um testemunho. E é a esse testemunho, de acordo com Halbwachs (2006, p. 29), que recorremos "para reforçar ou enfraquecer e também para completar o que sabemos de um evento sobre o qual já tivemos alguma informação".

De acordo com Bosi (2003), são nos testemunhos orais dos moradores antigos da região que se encontra um meio de resgatar e conhecer a memória local de uma cidade.

Quando as vozes das testemunhas se dispersam, se apagam, nós ficamos sem guia para percorrer os caminhos da nossa história mais recente: quem nos conduzirá em suas bifurcações e atalhos? Fica-nos a história oficial: em vez da envolvente trama tecida à nossa frente, só nos resta virar a página de um livro, unívoco testemunho do passado (BOSI, 2003, p. 70).

Há uma relação indissolúvel entre memória individual e memória coletiva, pois independente de o indivíduo guardar a lembrança em si, interage constantemente com a 
sociedade, com os diversos grupos dos quais, à medida que desenvolve sua vida, vai se tornando integrante (a família, os amigos, os celgas de trabalho, etc.) de forma que sua memória individual só existe na medida em que o indivíduo é integrante de um grupo, ou seja, a memória individual abrange dimensões coletivas, na medida em que as lembranças individuam encontram amparo nas lembranças de outros indivíduos que pertencem ao mesmo grupo.

\begin{abstract}
Nossas lembranças permanecem coletivas, e elas nos são lembradas pelos outros, mesmo que se trate de acontecimentos nos quais só nós estivemos envolvidos e com objetos que só nós vimos. É porque, em realidade, nunca estamos sós. Não é necessário que outros homens estejam lá, que se distingam materialmente de nós: porque temos sempre conosco e em nós uma quantidade de pessoas que não se confundem (HALBWACHS, 2006, p. $30)$.
\end{abstract}

Isso não quer dizer que haja um a anulação da memória individual, apenas que ela existe interligada a vários contextos. A memória individual se converte a qualidade de memória coletiva quando as lembranças pessoais se transformam em um conjunto de acontecimentos compartilhados por um grupo. A memória coletiva compreende a memória do grupo e os indivíduos que formam esse grupo se identificam com ela.

De acordo com Frochtengarten (2005), por meio da memória oral é possível reconstruir e vitalizar o passado vivido.

Porque representa uma forma de participação dos homens no domínio político, a memória oral levanta-se contra o isolamento humano. Quando habita o campo compartilhado por narrador e ouvinte, o passado de um homem ingressa no regime de inteligibilidade de outros homens, aproxima-se do passado do grupo (FROCHTENGARTEN, 2005, p. 373).

Resgatar a memória dos antropônimos significa reconstruir a história social dessa comunidade, significa realizar um movimento de aproximação do passado com vistas à ressignificação do presente, significa conhecer os aspectos sociopolíticos e culturais que permearam a época em que se deu a criação dessas escolas, significa recuperar e trazer à tona informações relacionadas à constituição do patrimônio cultural da comunidade, as quais se encontram subjacentes a esses nomes.

\title{
Considerações finais
}

Neste artigo buscou-se realizar uma reflexão acerca da possibilidade de se resgatar a história social de um determinado grupo por meio da análise dos antropônimos que nomeiam os estabelecimentos que fazem parte do contexto de tal grupo. Trata-se de evidenciar a importância de se conhecer a história das pessoas que 
tiveram seus nomes atribuídos a tais locais para a própria preservação da memória da sociedade.

O resgate dessa memória local visando ao conhecimento da comunidade de sua identidade sociocultural só se torna possível com a utilização da memória oral como fonte primeira de dados, uma vez que é no conhecimento dos moradores antigos de uma região que se encontra um meio de resgatar e conhecer a história e a memória local de uma região. O objetivo deste trabalho, portanto, residiu em apresentar o léxico, por meio dos antropônimos, enquanto patrimônio cultural imaterial.

Como palavras finais deste trabalho, é válido refletir sobre o que nos diz a psicóloga social Ecléa Bosi (2003, p. 16), “O movimento de recuperação da memória nas ciências humanas será moda acadêmica ou tem origem mais profunda como a necessidade de enraizamento? Do vínculo com o passado se extrai a força para formação de identidade".

\section{Referências}

ANDRADE, Karylleila dos Santos, DICK, Maria Vicentina de Paula do Amaral. A interdisciplinaridade no contexto da toponímia: reflexões iniciais de uma proposta aplicada ao ensino. In: ISQUERDO, Maria Aparecida; SEABRA, Maria Cândida T. C. de. Ciências do léxico. V. VI. Campo Grande: UFMS, 2012.

BENJAMIN, Walter. O Narrador: considerações sobre a obra de Nikolai Leskov. In. Magia e técnica, arte e política: ensaios sobre a literatura e história da cultura. São Paulo: Brasiliense, 1994, p.197-221.

BIDERMAN, M. T. As ciências do léxico. In. OLIVEIRA, Ana M. P. P.; ISQUERDO, Maria Aparecida. As ciências do léxico. Lexicologia, Lexicografia, Terminologia. V. I. Campo Grande: Ed. UFMS, 2001.

BOSI, Ecléa. O tempo vivo da memória: ensaios de psicologia social. São Paulo: Ateliê Editorial, 2003.

BRASIL. Secretaria de Educação Básica. Linguagens, códigos e suas tecnologias/Secretaria de Educação Básica. - Brasília: Ministério da Educação, Secretaria de Educação Básica, 2006. 239 p. (Orientações curriculares para o ensino médio; volume 1). Disponível no sítio http://portal.mec.gov.br/seb/arquivos/pdf/book_volume_01_internet.pdf. Acesso em 04 de março de 2014.

CARVALHINHOS, P. J. Toponímia- Onomástica e Lexicologia: o léxico toponímico como catalisador de fundo de memória. Estudo de caso: os sociotopônimos de Aveiro (Portugal. Revista USP. São Paulo, v. 56. pp. 172 - 179, 2003 (a). ISSN 0103-9989. 
Esgotado. Disponível em: <http://www.usp.br/revistausp/56/SUMARIO-56.htm>. Acesso em 02 de Ago. de 2014.

Etnotoponímia comparada e antroponímia: sistemas de nomeação e fundamentos do nome próprio. Cadernos do CNLF (CiFEFil), Rio de Janeiro, v. XII, n.9, pp. 106-117, $2009 \quad$ (b). Disponível em: <http://www.filologia.org.br/xiicnlf/09/completo_09.pdf>. Acesso em 02 de Ago. de 2014.

Interface onomástica/literatura: a toponímia, o espaço e o resgate de memória na obra Memórias da Rua do Ouvidor, de Joaquim Manuel de Macedo. Cadernos do CNLF (CiFEFil), Rio de Janeiro, v. XII, n.10, pp. 83-99, 2009 (a). Disponível em: <http://www.filologia.org.br/xiicnlf/10/completo_10.pdf>. Acesso em 02 de Ago. de 2014.

Princípios teóricos de Onomástica. Toponímia e Antroponímia. O nome próprio. Cadernos do CNLF. Rio de Janeiro: CiFEFil, Volume XI, no.02 - Livro dos Minicursos, p. 108-121, $2007 \quad$ (a). Disponível em: <http://www.filologia.org.br/xicnlf/3/Cad200320XICNLF.pdf>. Acesso em 02 de Ago. de 2014.

DICK, Maria Vicentina de Paula do Amaral. A motivação toponímica e a realidade brasileira. São Paulo: Arquivo do estado de SP, 1990.

Toponímia e antroponímia no Brasil: Coletânea de estudos. 2. ed. São Paulo: FFLCH/USP, 1992.

FROCHTENGARTEN, Fernando. A memória oral no mundo contemporâneo. Estudos Avançados, [S.1.], v. 19, n. 55, p. 367-376, dez. 2005. ISSN 1806-9592. Disponível em: <http://200.144.183.67/eav/article/view/10116>. Acesso em: 08 Ago. 2014.

GREIMAS, A. J. Dicionário de Semiótica. São Paulo: Cultrix, 1985.

HALBWACHS, Maurice. A Memória Coletiva. São Paulo: Centauro, 2006.

ISQUERDO, Maria Aparecida; KRIEGER, Maria da Graça. As ciências do léxico: Lexicologia, Lexicografia, Terminologia. V. II. Campo Grande: Ed. UFMS, 2004.

[Recebido: 11 ago. 2014 / Aceito: 12 nov. 2014] 